\title{
Desempenho de vacas de descarte recebendo dietas com ou sem monensina
}

\author{
Performance of cull cows receiving diets with or without monensin
}

\author{
Fernando Kuss ${ }^{\mathrm{I}}$ João Restle ${ }^{\mathrm{II}}$ Leonir Luis Pascoal' ${ }^{\mathrm{III}}$ Angélica Pereira dos Santos ${ }^{\mathrm{IV}}$ \\ Luis Fernando Glaszenapp de Menezes $^{\mathrm{V}}$ Milene Puntel Osmari $^{\mathrm{II}}$
}

\section{RESUMO}

Foi avaliado o desempenho em confinamento de vacas de descarte recebendo dietas sem ou com (200mg animal dia $^{-1}$ ) monensina sódica. A dieta continha $12,5 \%$ de proteína bruta e 2,99Mcal de energia digestível $\mathrm{kg}^{-1}$ de matéria seca, composta de $48 \%$ de volumoso e $52 \%$ de concentrado. Os consumos de matéria seca e energia digestível sofreram redução com a presença de monensina sódica na dieta, representando uma queda de 20,9\%. Esta redução no consumo de energia digestível por parte dos animais alimentados com monensina afetou negativamente o desempenho dos mesmos, demonstrando redução no ganho de peso de 22,6\%. Com maior consumo de alimento $e$, conseqüentemente, desempenho superior, os animais-controle apresentaram maior peso vivo ao abate $(527,49$ vs $498,00 \mathrm{~kg})$, sendo $5,8 \%$ mais pesados em relação aos animais alimentados com monensina. Quanto à conversão alimentar e eficiência energética, ambas as características não sofreram efeito significativo quando da presença de monensina na dieta (médias de 7,78 e 23,24; respectivamente). A presença de monensina sódica na dieta resultou em decréscimo do consumo de matéria seca e no ganho de peso, porém não alterou a conversão alimentar.

Palavras-chave: consumo, eficiência energética, fêmeas de corte, ganho de peso médio diário, ionóforo.

\section{ABSTRACT}

The feedlot performance of beef cull cows receiving diets without or with monensin (200mg animal ${ }^{-1}$ day $\left.^{-1}\right)$, was evaluated. The diet, $48 \%$ of roughage and $52 \%$ of concentrated, contained $12.5 \%$ of crude protein and 2.99 Mcal of digestible energy $\mathrm{kg}^{-1}$ of dry matter. The intake of dry matter and digestible energy was reduced $20.9 \%$ with the presence of monensin in the diet. The reduction in digestible energy intake by the animals fed with monensin affected negatively their performance, causing a decrease of $22.6 \%$ in their weight gain. With higher food intake and consequently superior performance, the control animals presented higher live weight at slaughter (527.49 vs $498.00 \mathrm{~kg}$ ), being $5.8 \%$ heavier in relation to the animals fed with monensin. The feed:gain ratio and energy efficiency, were not affected significantly by the presence of monensin in the diet (being the averages 7.78 and 23.24, respectively). The presence of monensin in diet resulted in reductions of dry matter intake and weight gain, however, it did not alter the feed:gain ratio.

Key words: average daily weight gain, beef culls, dry matter intake, energy efficiency, ionophore.

\section{INTRODUÇÃO}

Após o advento do melhoramento genético associado à busca de alternativas alimentares que resultassem em atingir-se o máximo do potencial produtivo dos bovinos de corte (ganho de peso e reprodução), surgiram os chamados aditivos alimentares, com a finalidade de maximizar ainda mais os índices produtivos. Entre os aditivos mais pesquisados, destacam-se os ionóforos, sendo a monensina sódica e a lassalocida sódica os ionóforos comumente utilizados no Brasil, tendo sido lançadas

\footnotetext{
IInstituto Agronômico do Paraná (IAPAR), Avenida Euzébio de Queiroz, s/n, CP 129, 84001-970, Bairro Uvaranas, Ponta Grossa, PR, Brasil. E-mail: fernando_kuss@iapar.br. Autor para correspondência.

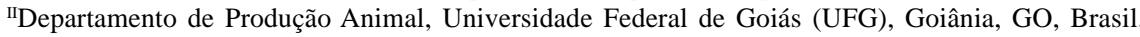

IIIDepartamento de Zootecnia, Universidade Federal de Santa Maria (UFSM), Santa Maria, RS, Brasil.

${ }^{\text {IV}}$ Programa de Pós-graduação em Zootecnia, Universidade Federal do Rio Grande do Sul (UFRGS), Porto Alegre, RS, Brasil.

vPrograma de Pós-graduação em Zootecnia, Universidade Federal de Santa Maria (UFSM). Santa Maria, RS, Brasil.

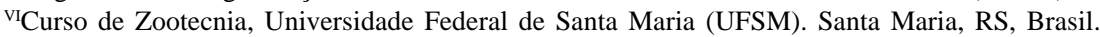


em 1983 e 1986, respectivamente (PASCOAL et al., 2000). Originalmente a monensina sódica foi usada na prevenção de coccidiose em frangos de corte, porém, mais tarde, outros trabalhos revelaram seus efeitos na regulação da fermentação ruminal e seus produtos (McGUFFEY et al., 2001; OLIVEIRA et al., 2005). Os melhores desempenhos obtidos com o emprego do ionóforo são atribuídos, principalmente, à maior eficiência do metabolismo energético e nitrogenado no rúmen, ocorrendo ainda diminuição de distúrbios metabólicos, como a acidose e o timpanismo.

A monensina sódica aumenta a produção de ácido propiônico no rúmen, resultando em decréscimo na proporção do ácido acético e butírico. Esse efeito é resultado da ação seletiva na população microbiana, afetando negativamente as bactérias grampositivas (KONE et al., 1989). A ação contra as bactérias gram-positivas ocorre por causa do sistema de transporte de íons através das membranas celulares das bactérias. Essas bactérias não possuem, como as gram-negativas, sistema de transporte de elétrons acoplado à síntese de ATP e, assim, a maioria não sobrevive à ação do ionóforo (McGUFFEY et al., 2001).

Quanto ao efeito da monensina sobre o desempenho, POTTER et al. (1986), avaliando uma série de experimentos (24 estudos) em pastejo com suplementação, verificaram uma superioridade de 16,3\% no ganho de peso, quando foram adicionados $200 \mathrm{mg}$ de monensina por animal ao suplemento. Já quanto ao desempenho em confinamento (12 experimentos), os autores reportaram incremento no ganho de peso e consumo de matéria seca de 14,1 e $3,1 \%$, respectivamente, e uma melhora na conversão alimentar de $15,3 \%$. Em trabalhos nacionais revisados por PASCOAL et al. (2000), os autores reportaram incremento no ganho de peso de $4,5 \%$ e melhora na conversão alimentar de $7 \%$ ao longo da terminação de novilhos e novilhas em confinamento.

Dessa forma, a utilização da monensina pode ser uma alternativa para maximizar a eficiência energética dos alimentos ingeridos, com conseqüente melhora na conversão alimentar, principalmente em categorias menos eficientes na conversão do alimento em ganho de peso, como é o caso de vacas de descarte, devido a sua maior exigência energética de mantença e ganho de peso. No trabalho realizado por RESTLE et al. (2001), os autores verificaram redução no consumo de matéria seca $\left(12,76\right.$ vs $\left.12,03 \mathrm{~kg} \mathrm{dia}^{-1}\right)$ sem alterar o ganho de peso $\left(1,74\right.$ vs $\left.1,80 \mathrm{~kg} \mathrm{dia}^{-1}\right)$ e a conversão alimentar $(7,26$ vs 7,41$)$ de vacas e novilhas de descarte terminadas em confinamento com dietas com (150mg animal ${ }^{-1} \mathrm{dia}^{-1}$ ) e sem monensina sódica.
Considerando que em torno de 50\% dos animais abatidos no Brasil são provenientes dessa categoria animal (ANUALPEC, 2005), é importante que sejam realizadas mais pesquisas para verificar o efeito deste ionóforo sobre o desempenho na fase de terminação de vacas de descarte. Nesse sentido, o objetivo deste trabalho foi avaliar o desempenho de vacas de descarte terminadas em confinamento, submetidas a dietas com ou sem adição de monensina sódica.

\section{MATERIAL E MÉTODOS}

O estudo foi conduzido no Setor de Bovinocultura de Corte do Departamento de Zootecnia da Universidade Federal de Santa Maria (UFSM). Foram utilizadas 24 vacas de descarte resultante do cruzamento alternado Charolês-Nelore, as quais, ao início do período experimental, apresentavam, em média, 8,5 anos de idade, $387,83 \mathrm{~kg}$ de peso vivo e 2,35 pontos de escore da condição corporal. Os animais foram arranjados em lotes de dois animais, permanecendo 92 dias em confinamento, recebendo dietas sem ou com $\left(200 \mathrm{mg}^{-1}\right.$ animal $^{-1}$ dia) monensina sódica. A dieta continha 12,5\% de proteína bruta e 2,99Mcal de energia digestível kg ${ }^{-1}$ de matéria seca (MS), composta de $48 \%$ de volumoso (silagem de milho) e 52\% de concentrado (92\% de farelo de trigo; 6,8\% de calcário calcítico e $1,2 \%$ de sal comum, com base na MS).

Antecedendo o período experimental, os animais foram adaptados durante 21 dias à dieta e ao manejo do confinamento. Os animais foram pesados no início do período experimental de 92 dias, subdivididos em quatro períodos de 21 dias, sendo o último de oito dias, ao final dos quais os animais eram pesados, após um jejum de sólidos de 14 horas, para acompanhamento da evolução do peso vivo e escore de condição corporal, utilizando-se uma escala de 1 a 5 pontos, sendo 1 animais muito magros e 5 animais muito gordos, conforme metodologia descrita por RESTLE(1972).

A alimentação foi subdividida em duas refeições ao dia, uma pela parte da manhã e outra pela parte da tarde, sendo que o volumoso foi misturado ao concentrado no cocho no momento da alimentação. Na manhã do dia seguinte, antes da primeira alimentação, foram retiradas e pesadas as sobras de alimento para cálculo do consumo de matéria seca dos lotes e ajuste da quantidade oferecida, uma vez que as sobras foram mantidas ao redor de $10 \%$ do total oferecido. A concentração de energia digestível (ED) dos alimentos foi calculada levando-se em conta a digestibilidade in vitro da matéria orgânica (ARC, 1980): ED=MOD (matéria orgânica digestível) x 0,19 / 4,184. 
Os ingredientes do concentrado foram coletados a cada período de 21 dias, moídos e acondicionados em sacos plásticos hermeticamente fechados e identificados. A silagem também foi amostrada a cada 21 dias, sendo posteriormente secada em estufa a $65^{\circ} \mathrm{C}$ até atingir peso constante, para determinação do percentual de matéria seca. A seguir, as amostras de concentrado e silagem foram processadas em um moinho tipo Willey com peneira de $2 \mathrm{~mm}$ e encaminhadas ao laboratório de análises bromatológicas.

As características analisadas foram: ganho de peso médio diário (GMD); escore de condição corporal (ECC); conversão alimentar (CA); consumo de matéria seca (CMS); CMS em relação a $100 \mathrm{~kg}$ de peso vivo - PV (CMSPV); CMS por unidade de tamanho metabólico em g ${ }^{-1} \mathrm{~kg}$ de $\mathrm{PV}^{0,75}$ (CMSTM); consumo de energia digestível (CED); CED em relação a 100kg de PV (CEDPV); CED por unidade de tamanho metabólico em g $^{-1} \mathrm{~kg}$ de $\mathrm{PV}^{0,75}$ (CEDTM) e eficiência energética (EE). Foi utilizado como covariável o peso inicial dos animais.

O delineamento experimental utilizado foi o inteiramente casualizado, sendo os dados submetidos à análise de variância pelo teste F. As médias das variáveis dependentes significativamente afetadas pelas variáveis independentes, segundo análise de variância, foram comparadas através do teste da probabilidade da diferença (pdiff). A análise estatística foi realizada utilizando-se o procedimento GLM do SAS (1997).

\section{RESULTADOS E DISCUSSÃO}

$\mathrm{Na}$ tabela 1, encontram-se os resultados referentes ao consumo de matéria seca e consumo de energia digestível expressos em valores absolutos (CMS e CED), em percentagem do peso vivo (CMSPV e CEDPV) e por unidade de tamanho metabólico (CMSTM e CEDTM), segundo a dieta. Verificou-se que, em todas as formas de expressão de consumo, houve redução com a presença de monensina sódica, representando uma redução de 20,9\% no CMS. Trabalhando com a mesma categoria animal, RESTLE et al. (2001) também observaram similar comportamento, porém a redução de consumo voluntário de matéria seca foi menor, 9,1\%. Já no estudo de ROSO \& RESTLE (2001), avaliando o efeito da lasalocida sódica adicionada ao sal comum sobre o desempenho de fêmeas de corte em pastagem cultivada durante a recria, os autores observaram redução no consumo de forragem, o que permitiu o aumento da carga animal e ganho de peso ha-1 ${ }^{-1}$ Demais estudos, com novilhos em fase de terminação em confinamento, também descrevem redução do consumo de matéria seca quando adicionado monensina à dieta (GILL et al., 1976; LANA \& FOX, 2001; OLIVEIRA et al., 2005).

No estudo de BAILE et al. (1979), os autores atribuíram o menor consumo à aversão dos animais ao alimento quando submetidos às dietas com monensina. Segundo RESTLE et al. (2001), com o avanço da idade das vacas, os animais apresentaram paladar mais desenvolvido, sendo mais sensíveis à presença da monensina na dieta. No presente estudo, o consumo de monensina foi de $200 \mathrm{mg}$ animal ${ }^{-1} \mathrm{dia}^{-1}$, ao passo que RESTLE et al. (2001) utilizaram concentração menor (150mg animal ${ }^{-1} \mathrm{dia}^{-1}$ ). Dessa forma, explica-se a redução de consumo mais drástica no presente trabalho. GOONDRICH et al. (1984), sumarizando 29 estudos com adição de monensina à dieta, concluíram que o consumo voluntário decresce à medida que se incrementa a quantidade de monensina fornecida.

Tabela 1 - Médias e desvios-padrão para consumo de alimento e de energia, conversão alimentar e energética de vacas de descarte terminadas em confinamento recebendo dietas com ou sem monensina.

\begin{tabular}{|c|c|c|c|c|}
\hline \multirow{2}{*}{ Itens } & \multicolumn{2}{|c|}{ Dieta } & \multirow{2}{*}{$\mathrm{DP}^{1}$} & \multirow{2}{*}{$\mathrm{P}^{2}$} \\
\hline & Com monensina & Sem monensina & & \\
\hline $\mathrm{CMS}^{3}, \mathrm{~kg}$ & 9,25 & 11,70 & 0,43 & 0,0029 \\
\hline $\mathrm{CMSPV}^{4}, \%$ & 2,10 & 2,55 & 0,09 & 0,0067 \\
\hline $\mathrm{CMSTM}^{5}, \mathrm{~g}^{-1} \mathrm{~kg}^{0,75}$ & 96,01 & 118,03 & 4,11 & 0,0043 \\
\hline $\mathrm{CED}^{6}, \mathrm{Mcal}^{-1}$ dia & 27,65 & 34,95 & 1,27 & 0,0029 \\
\hline $\mathrm{CEDPV}^{7}, \%$ & 6,26 & 7,63 & 0,27 & 0,0067 \\
\hline $\mathrm{CEDTM}^{8}, \mathrm{Mcal}^{-1} \mathrm{~kg}^{0,75}$ & 286,92 & 352,74 & 12,27 & 0,0043 \\
\hline $\mathrm{CA}^{9}$ & 7,89 & 7,67 & 0,46 & 0,7441 \\
\hline $\mathrm{EE}^{10}$ & 23,57 & 22,91 & 1,38 & 0,7441 \\
\hline
\end{tabular}

${ }^{1}$ Desvio padrão. ${ }^{2}$ Probabilidade. ${ }^{3}$ Consumo de matéria seca. ${ }^{4} \mathrm{CMS}$ em relação a $100 \mathrm{~kg}$ de peso vivo. ${ }^{5} \mathrm{CMS}$ por unidade de tamanho metabólico. ${ }^{6}$ Consumo de energia digestível (CED). ${ }^{7} \mathrm{CED}$ em relação a $100 \mathrm{~kg}$ de peso vivo. ${ }^{8} \mathrm{CED}$ por unidade de tamanho metabólico. ${ }^{9}$ Conversão alimentar (CA). ${ }^{10}$ Eficiência energética (EE). 
Essa redução drástica no consumo voluntário de matéria seca nos animais alimentados com a dieta com presença de monensina provocou, consequentemente, redução no consumo de energia digestível de 34,95 para 27,65Mcal animal ${ }^{-1} \mathrm{dia}^{-1}$. Similar comportamento também foi observado por RESTLE et al. (2001) com animais da mesma categoria (29,99 para 28,29Mcal animal ${ }^{-1} \mathrm{dia}^{-1}$, respectivamente, para os animais sem e com monensina à dieta).

A redução no consumo de energia digestível por parte dos animais alimentados com monensina foi suficiente para afetar negativamente o desempenho dos mesmos. Observou-se que o decréscimo no ganho de peso dos animais alimentados com monensina para com os animais-controle (sem monensina) acompanhou o comportamento encontrado no consumo de matéria seca, sendo esta redução de 22,6\% (Tabela 2).

Com maior consumo de alimento e, conseqüentemente, desempenho superior, os animaiscontrole apresentaram maior peso vivo ao abate (Tabela 2), sendo 5,8\% mais pesados em relação aos animais alimentados com monensina. Embora os animaiscontrole fossem mais pesados ao abate, o estado de condição corporal ao abate (ECCF) não diferiu significativamente entre os animais dos dois tratamentos. No entanto, pode-se verificar que os animais-controle apresentaram escore de condição corporal próximos a gordos ( 4,0 pontos), ao passo que os animais com monensina demonstraram estado pouco superior a regular (3,5 pontos), segundo a classificação proposta por RESTLE (1972). RESTLE et al. (2001) também não observaram diferença significativa no escore de condição corporal entre animais da mesma categoria alimentados com ou sem monensina.

Ainda na tabela 2, estão descritos os resultados referente à conversão alimentar e eficiência energética. Observa-se que ambas as características não sofreram efeito significativo quando da presença de monensina na dieta. Embora tenha ocorrido redução no consumo de alimento, também o ganho de peso foi inferior nos animas tratados com monensina, proporcionando conversão alimentar similar entre os grupos testados. Trabalhando com terminação de novilhos de corte em confinamento com dietas com e sem monensina, alguns autores (ZINN \& BORQUES, 1993; SALLES \& LUCCI, 2000) também relataram não ter encontrado efeito significativo entre os animais dos dois tratamentos avaliados. No entanto, LANA \& FOX (2001) descrevem que a adição de monensina interagiu com a fonte de nitrogênio (uréia ou farelo de soja) e a presença de óleo (com ou sem óleo de soja) na dieta sobre a conversão alimentar, demonstrando que a monensina melhorou a conversão nas dietas contendo como fonte de nitrogênio o farelo de soja, sem a utilização de óleo de soja. Além disso, os mesmos autores mostraram que a adição de monensina não alterou a conversão dos animais alimentados com dietas contendo uréia, porém resultou em redução da conversão quando os animais foram alimentados com dietas que apresentavam farelo mais óleo de soja. Existem na literatura pesquisas que também demonstram que a monensina melhora significativamente a conversão alimentar (GILL et al., 1976; GOODRICH et al., 1984; OSCAR et al., 1987).

Comparando animais de similar categoria terminados em regime de confinamento, os animais do presente estudo foram mais eficientes na conversão do alimento em ganho de peso, quando comparados aos animais utilizados por RESTLE et al. (2001), os quais também testaram dietas com e sem a adição de monensina ( 8,30 vs 8,25 , respectivamente), não verificando diferença significativa entre os tratamentos testados. A conversão alimentar das vacas deste estudo é considerada satisfatória, sendo estes valores similares ao verificados em novilhos de 24 meses terminados em confinamento (FATURI et al., 2003; RESTLE et al., 2004). Esta melhor eficiência na

Tabela 2 - Médias e desvios-padrão para peso inicial e final, escore de condição corporal inicial (ECCI) e final (ECCF) e ganho de peso médio diário (GMD) de vacas de descarte terminadas em confinamento recebendo dietas com ou sem monensina.

\begin{tabular}{|c|c|c|c|c|}
\hline \multirow{2}{*}{ Itens } & \multicolumn{2}{|c|}{ Dieta } & \multirow{2}{*}{$\mathrm{DP}^{1}$} & \multirow{2}{*}{$\mathrm{P}^{2}$} \\
\hline & Com monensina & Sem monensina & & \\
\hline Peso inicial, kg & 386,83 & 388,83 & 10,12 & 0,8917 \\
\hline Peso final, kg & 498,00 & 527,49 & 21,25 & 0,3525 \\
\hline ECCI, pontos & 2,33 & 2,32 & 0,06 & 0,9413 \\
\hline ECCF, pontos & 3,61 & 3,80 & 0,31 & 0,6766 \\
\hline GMD, kg & 1,20 & 1,55 & 0,11 & 0,0559 \\
\hline
\end{tabular}

${ }^{1}$ Desvio padrão;

${ }^{2}$ Probabilidade.

Ciência Rural, v.38, n.1, jan-fev, 2008. 
conversão do alimento em ganho de peso se deve à maior concentração energética por kg de matéria seca ingerida (2,99Mcal de energia digestível $\mathrm{kg}^{-1}$ de matéria seca), ao passo que, no estudo de RESTLE et al. (2001), a concentração energética foi inferior devido à relação volumoso:concentrado ser menor (65:35), sendo de 2,32Mcal de energia digestível $\mathrm{kg}^{-1}$ de matéria seca.

\section{CONCLUSÕES}

A presença de monensina sódica à dieta não traz benefício quanto ao desempenho de vacas terminadas em confinamento, pois atua como limitante no consumo de alimento e, consequentemente, no ganho de peso.

\section{AGRADECIMENTOS}

Ao Conselho Nacional de Desenvolvimento Científico e Tecnológico (CNPq), pela concessão de bolsas de estudos aos alunos de pós-graduação (doutorado).

\section{REFERÊNCIAS}

AGRICUlTURAL RESEARCH COUNCIL - ARC. The nutrients requeriments of ruminants livestock. London: Technical review by on Agricultural Research Council Working Patry, 1980. 351p.

ANUALPEC. Anuário estatístico da produção animal. FNP. São Paulo: Camargo Soares, 2005. 400p.

BAILE, C.A. et al. Feeding behavior changes of cattle during introduction of monensin with roughage or concentrate diets. Journal of Animal Science. v.48, n.6, p.1501-1508, 1979

FATURI et al. Grão de aveia preta em substituição ao grão de sorgo para alimentação de novilhos na fase de terminação. Revista Brasileira de Zootecnia, v.32, n.2, p.437-448, 2003.

GILL, D.R. et al. High, medium and low corn silage diets with and without monensina for feedlot steers. Journal of Animal Science, v.43, n.2, p.363-368, 1976.

GOODRICH, R.D. et al. Influence of monensin the performance of cattle. Journal of Animal Science, v.58, n.6, p.14841498, 1984.

KONE, P. et al. Effect of the combination of monensin and isoacids on rumen fermentation in vitro. Journal of Dairy Science, v.72, p.2767-2771, 1989.

LANA, R.P.; FOX, D.G. Interações entre monensina sódica, óleo de soja e fontes de nitrogênio no desempenho de novilhos Aberdeen Angus em confinamento. Revista Brasileira de Zootecnia, v.30, n.1, p.247-253, 2001.
McGUFFEY R.K. et al. Ionophore for dairy cattle: corrent status and future outlook. Journal Dairy Science, v.84 (Suppl.), p.E194-E203, 2001.

MOLETTA, J.L.; RESTLE, J. Desempenho em confinamento de novilhos de diferentes grupos genéticos. Ciência Rural, v.22, n.2, p.227-233, 1992

OLIVEIRA, M.V.M. et al. Influência da monensina e na fermentação ruminal de bovines recebendo dietas com teores baixo e alto de proteína. Revista Brasileira de Zootecnia, v.34, n.5, p.1763-1774, 2005.

OSCAR, T.P. et al. Performance, methanogenesis and nitrogen metabolismo of finishing steers fed monensin and nickel. Journal of Animal Science, v.64, p.887-896, 1987.

PASCOAL, L.L. et al. Uso de ionóforos e minerais no confinamento e em pastagem cultivada. In.: RESLTE, J. Eficiência na produção de bovinos de corte. Santa Maria: UFSM, 2000. p.304-332.

POTTER, E.L. et al. Effects of monensin on the performance of cattle on pasture or fed harvested forages in confinement. Journal of Animal Science, v.63, p.583, 1986.

RESTLE J. Comportamento reprodutivo do rebanho de gado de corte da fazenda experimental de criação experimental agronômica da UFRGS. 1972. 96f. Seminário (Disciplina de Técnicas de Pesquisas) - Curso de Pósgraduação em Agronomia, Universidade Federal do Rio Grande do Sul.

RESTLE et al. Terminação em confinamento de vacas e novilhas sob dietas com ou sem monensina sódica. Revista Brasileira de Zootecnia, v.30, n.6, p.1801-1812, 2001.

RESTLE et al. Substituição do grão de sorgo por casca de soja na dieta de novilhos terminados em confinamento. Revista Brasileira de Zootecnia, v.33, n.4, p.1009-1015, 2004.

ROSO, C.; RESTLE, J. Lasalocida sódica suplementada via sal para fêmeas de corte mantidas em pastagem de estação fria. Revista Brasileira de Zootecnia, v.30, n.3, p.830-834, 2001.

SALLES, M.S.V.; LUCCI, C.S. Monensina para bezerros em crescimento acelerado. 1. Desempenho. Revista Brasileira de Zootecnia, v.29, n.2, p.573-581, 2000.

SAS INSTITUTE. SAS/STAT user's guide: statistics. 8.ed. Verson 6.11. Cary, 1997. V.6, 943p.

SCHELLING, G.T. Monensin mode of action in the rumen. Journal of Animal Science, v.58, n.6, p.1518-1527, 1984.

ZINN, R.E.; BORQUES, J.L. Influence of sodium bicarbonate and monensin in utilization of a fat-supllemented, high-energy growing-finishing diet by feedlot steers. Journal of Animal Science, v.71, p.18-25, 1993. 